\title{
Rede de Proteção: O Olhar de Profissionais do Sistema de Garantia de Direitos
}

\author{
Suane Pastoriza Faraj ${ }^{1}$ \\ Entidade Palotina de Educação e Cultura, Santa Maria, RS, Brasil \\ Aline Cardoso Siqueira \\ Dorian Mônica Arpini \\ Departamento de Psicologia e Programa de Pós-Graduação em Psicologia \\ da Universidade Federal de Santa Maria, Santa Maria, RS, Brasil
}

\begin{abstract}
Resumo
$\mathrm{O}$ artigo aborda a rede de proteção às crianças e adolescentes a partir do olhar dos profissionais que atuam no eixo da defesa no Sistema de Garantia de Direitos. O objetivo desse estudo foi conhecer e compreender o funcionamento da rede de proteção às crianças e aos adolescentes em situação de violência. Foi realizada uma pesquisa qualitativa, com a utilização de entrevistas semi-estruturadas, as quais foram realizadas junto a Delegacia de Proteção a Criança e ao Adolescente, Ministério Público e Conselhos Tutelares de uma cidade de porte médio do interior do Rio Grande do Sul. Os resultados indicam que os profissionais tem clareza do trabalho em rede e de seu funcionamento como estratégia para a superação da fragmentação do trabalho. No entanto, ao mesmo tempo, destacaram a importância do fortalecimento do diálogo e de espaços de aproximação entre os diferentes órgãos que compõem o Sistema de Garantia de Direitos, como forma de superar as lacunas existentes. As considerações finais destacam a importância da construção de novos dispositivos de trabalho superando o isolamento que teria marcado as práticas profissionais e a formação dos diferentes núcleos, a fim de promover o atendimento integral preconizado no Estatuto da Criança e do Adolescente (ECA).
\end{abstract}

Palavras-chaves: Violência contra criança e adolescente, garantia de direitos, rede de proteção.

\section{Network of Protection: The Look of Profissionals Rights Protection System}

\begin{abstract}
The aim of this study is to know the perception of the prosecutor, the chief of police and child protection agents about the network of protection developed for children and adolescents facing a situation of violence. Five professionals were interviewed and the emerging data evidence that, through permanent dialogue and communication among its members, the network represents joint efforts, aiming to guarantee and protect the rights of children and adolescents. The need of strengthening the network was identified, especially, through dialogue among its agents, so as to promote the integral care recommended
\end{abstract}

Endereço para correspondência: Duque de Caxias, $n^{\circ}$ 2232, Apto. 302, Bairro Centro, Santa Maria, RS, Brasil 97015-100. E-mail: suanef@yahoo.com.br

Este artigo é um recorte da dissertação de mestrado intitulada "A notificação da violência, o atendimento psicológico e a rede de proteção da criança e do adolescente: o olhar de profissionais do Sistema de Garantia de Direitos" de autoria de Suane Pastoriza Faraj, do Programa de Pós-Graduação em Psicologia da Universidade Federal de Santa Maria. 
in the Statute of the Child and Adolescent (SCA). Strategies for consolidation and reinforcement of the network of protection are discussed.

Keywords: Violence against children and adolescents, guarantee of rights, network of protection

\section{Red de Protección: La Mirada de Profesionales del Sistema de Garantía de Derechos}

\section{Resumen}

En este artículo se aborda la red de protección a los niños y adolescentes bajo la visión de los profesionales que trabajan en el eje de la defensa en el sistema de garantía de derechos. El objetivo de este estudio fue conocer y comprender el funcionamiento de la red de protección para los niños y adolescentes en situación de violencia. Fue realizada investigación cualitativa a través de entrevistas semi-estructuradas, las cuales fueron hechas con la Policía de Niños y Adolescente, el Ministerio Público y Consejos Tutelares de una ciudad de porte medio el interior de Río Grande do Sul. Los resultados indican que los profesionales están seguros de que el trabajo en red y su funcionamiento son una buena estrategia para superar la fragmentación del trabajo. Sin embargo, al mismo tiempo, subrayaron la importancia de fortalecer el diálogo y los espacios de acercamiento entre los diferentes organismos que conforman el sistema de protección de derechos como una forma de superar las carencias existentes. Las consideraciones finales destacan la importancia de la construcción de nuevos dispositivos de trabajo superando el aislamiento que ha marcado las prácticas profesionales de los diferentes núcleos de formación, con la finalidad de promover la atención integral que preconiza el Estatuto del Niño y del Adolescente (ECA).

Palabras clave: Violencia contra los niños y adolescentes, garantía de los derechos, red de seguridad.

$\mathrm{Na}$ atualidade, as crianças e os adolescentes são considerados sujeitos em condições peculiares de desenvolvimento e têm seus direitos assegurados pelo Estatuto da Criança e do Adolescente (ECA, 1990, Lei $n^{\circ}$ 8.069/1990). Esta legislação preconizou a doutrina da proteção integral e instituiu mudanças significativas na política de atendimento voltada para a criança e adolescente, especialmente aqueles em situação de violência. Um longo caminho tem sido trilhado para se romper com as antigas práticas de cuidado às crianças e aos adolescentes, as quais tinham caráter essencialmente assistencialista. A constituição de uma rede de proteção, que reúne ações conjuntas e articuladas no atendimento voltado para a infância e adolescência, representa um avanço no campo da proteção integral (Rizzini, Rizzini, Naiff, \& Batista, 2007). Para compreender no que consiste e quais são as atribuições da rede de proteção, é importante conhecer o percurso histórico dos direitos da criança e do adolescente, bem como as políticas públicas voltadas a essa população.

\section{Percurso Histórico dos Direitos e Políticas Voltadas para a Infância e Adolescência}

Os direitos da criança e do adolescente na legislação brasileira vêm sendo construídos no decorrer da história, assim como as políticas públicas de proteção destinadas a esta população. As crianças e os adolescentes não foram reconhecidos como sujeitos de direitos na sociedade e no ordenamento jurídico brasileiro até a Constituição Federativa de 1988 (V. P. Faleiros, 2004; V. P. Faleiros \& Faleiros, 2008). A preocupação em relação à população infantil e juvenil, do período colonial até a metade do século XIX, esteve voltada para a assistência, com caráter eminentemente caritativo e religioso, destinada àquelas crianças e adolescentes considerados rejeitados e/ou abandonados (Rizzini \& Rizzini, 2004). As Câmaras Municipais eram responsáveis, formalmente, pela assistência a esta parcela da população, no entanto, a proteção era delegada a outros serviços ou instituições através do 
estabelecimento dos convênios com as Santas Casas de Misericórdia e contratos firmados com as denominadas amas-de-leite. Com relação às crianças abandonadas, muitas foram acolhidas por famílias ou indivíduos, correspondendo a um sistema informal de proteção (Marcílio, 2006).

As primeiras instituições formais, que surgiram no século XVIII, foram as Rodas dos Expostos, os Recolhimentos para meninas e os Seminários para meninos (Marcílio, 2006). A Roda dos Expostos constituía-se em:

um dispositivo onde se colocavam os bebês que se queriam abandonar. Sua forma cilíndrica, dividida ao meio por uma divisória, era fixada no muro ou na janela da instituição. No tabuleiro inferior e em sua abertura externa, o expositor depositava a criancinha enjeitada. A seguir, ele girava a roda $\mathrm{e}$ a criança já estava do outro lado do muro. Puxava-se uma cordinha com uma sineta, para avisar a vigilante ou rodeira que um bebê acabava de ser abandonado e o expositor furtivamente retirava-se do local, sem ser identificado. (Marcílio, 2006, p. 55)

Nesse período, não estava em vigência nenhuma lei de proteção a essas crianças. Inclusive, nas duas primeiras Constituições Brasileiras - a Constituição Imperialista de 1824 e a Constituição Republicana de 1891 - houve uma omissão com relação à proteção da criança e do adolescente. O código criminal do Império (1830), por sua vez, estabeleceu que os menores de quatorze anos não poderiam ser submetidos a penas, a menos que os juízes determinassem, sendo recolhidos nas Casas de Correção, não ultrapassando os dezessete anos de idade (Azambuja, 2011; Rizzini, 2002; C. M. A. Santos, 2005). Já o Código Penal de 1890, em relação à responsabilidade penal da criança, parece ter sido um retrocesso, uma vez que estabeleceu o limite de nove anos de idade. Essa legislação presumia o recolhimento a estabelecimentos disciplinares de adolescentes com idades entre quatorze e vinte um anos incompletos, quando avaliados como "vadios" (Azambuja, 2011; Marcílio, 2006).

Em torno da década de 1870, a assistência à infância, apesar de ainda ter aspectos caritativos, evoluiu para um caráter filantrópico. Al- gumas iniciativas foram realizadas pelo Estado após a Proclamação da República em 1889, como a criação das casas correcionais para os menores (termo usado para referir-se à criança e ao adolescente até o Estatuto da Criança e do Adolescente), que tinham como objetivo corrigir o comportamento desviante ou transgressor. A criação dos tribunais especiais, do Conselho de Assistência e Proteção aos Menores e do Abrigo de Menores também se destacam como ações estatais importantes neste período (V. P. Faleiros, 2004; V. P. Faleiros \& Faleiros, 2008). A partir do início do século XX, questões referentes à conceituação da infância $\mathrm{e}$ às suas condições sociais e jurídicas, assim como o atendimento a esta parcela da população, começaram a ser repensados (Azambuja, 2011; Marcílio, 2006).

$\mathrm{O}$ século XX foi marcado por três legislações voltadas para as questões referentes à infância e adolescência: o Código de Menores de 1927 (Decreto $\mathrm{n}^{\mathrm{o}}$ 17943-A, de 12 de outubro de 1927), o Código de Menores de 1979 (Lei nº. 6.697, de 10 de outubro de 1979) e o ECA (Lei nº 8.069, de 13 de julho de 1990). O primeiro estabeleceu a "Doutrina do Direito Penal do Menor", sendo seu foco a criança e o adolescente "menor abandonado" ou "delinquente". Através deste código, a assistência e a proteção dos abandonados e delinquentes passaram a ser assumidas pelo Estado. O estabelecimento de um processo especial para julgar os menores delinquentes com idade entre 14 e 18 anos incompletos, excluindo a responsabilidade penal aos menores de quatorze anos também foi priorizado neste código (V. P. Faleiros, 2004; Mendes, 2008; Rizzini, 2002). No âmbito penal, no ano de 1940, foi aprovado o Decreto-Lei $n^{\circ} 2.848$ que instituiu o Código Penal Brasileiro, que está em vigor até o momento, estabelecendo a imputabilidade penal a partir dos 18 anos.

Um instrumento social, o Serviço de Assistência ao Menor (SAM), instituído através do Decreto-lei n ${ }^{\circ} 3.733 / 41$, voltado para a assistência à criança e ao adolescente, surgiu em 1941. O SAM tinha o intuito de oferecer apoio aos menores carentes, abandonados e infratores, prevenindo a criminalidade infantil por meio de ações educativas, porém o que predominou foram as 
ações de caráter mais repressivo e corretivo (V. P. Faleiros \& Faleiros, 2008; Rizzini, 2002).

Nas décadas de 40 e 50, no âmbito internacional, tem-se documentos e acordos relacionados à infância, entre eles, a Declaração dos Direitos Humanos, proclamada em 1948 pela Organização das Nações Unidas (ONU), estabelecendo que todo ser humano é um ser de direitos e a Declaração dos Direitos da Criança, proclamada em 1959, também pela ONU (Azambuja, 2011). Na década de 60, o Estado brasileiro tornou-se o responsável principal pela assistência e proteção à infância pobre e desviante. A Lei $\mathrm{n}^{\circ} 4.513$ de $1^{\circ}$ de dezembro de 1964 instituiu a Fundação Nacional de Bem-Estar do Menor (FUNABEM) na esfera nacional. Mais tarde, em âmbito estadual, foram criadas as unidades da Fundação Estadual de Bem-Estar do Menor (FEBEMs), que estavam voltadas quase que exclusivamente para a reclusão do adolescente que cometia um ato infracional (Marcílio, 2006; C. M. A. Santos, 2005). A FUNABEM tinha como objetivo inicial instituir o Anti-SAM, tendo autonomia administrativa e financeira para formular e implantar a Política Nacional do Bem-Estar do Menor (Rizzini \& Rizzini, 2004; C. M. A. Santos, 2005). A prevenção e o controle dos menores por meio de ações voltadas para a repressão e a punição estavam instituídos na FUNABEM e as FEBEMs visavam ao cumprimento das providências indicadas pelo Juiz (C. M. A. Santos, 2005).

No ano de 1979, foi promulgado o segundo Código de Menores, que revogou a "Doutrina do Direito Penal do Menor" e estabeleceu a "Doutrina do Menor em Situação Irregular". Esse Código de Menores também não estava voltado para todas as crianças e adolescentes, mas apenas para aqueles que se encontravam nas situações descritas como irregulares, entre eles, as vítimas de maus tratos, as vítimas da omissão dos pais ou responsáveis e os autores de infração penal. A Lei preconizava que o "Juiz de Menores" poderia decidir, de maneira autoritária e isolada, a situação da criança/adolescente em situação irregular (Giaqueto, 2006).

Destaca-se contudo, que durante os anos de 1980 e 1990, o Brasil viveu um momento histórico importante sobretudo pela abertura demo- crática. Surgiu nesse cenário um documento intitulado Estatuto da Criança e do Adolescente (1990), que altera a concepção dos direitos das crianças e dos adolescentes, fruto de uma intensa mobilização da sociedade civil. Nesse cenário, surgiu também a Constituição Federativa do Brasil de 1988 - chamada de Constituição Cidadã - a qual alterou a direção da história dos direitos da criança e do adolescente, reconhecendo-os como sujeitos com direitos e garantias, antecipando o que se encontraria dois anos mais tarde no texto do ECA (Fonseca, 2004). Como complementou Fonseca (2004), o novo estatuto não foi fruto apenas do clima político brasileiro, mas também fez parte de um movimento mundial, que alterou em muitos países a legislação sobre as crianças e adolescentes como a Convenção dos Direitos da Criança das Nações Unidas (1989), a Lei do Bem Estar da Criança de 1987, o Estatuto Africano do Bem-Estar da Criança de 1987, o Código Inglês da Criança de 1989, entre outros documentos. Fica claro que as mudanças ocorridas no Brasil refletiram os debates, fóruns e as mudanças ocorridas no cenário internacional em relação aos direitos das crianças. Neste cenário, destacou-se também o tratado internacional aprovado pela Assembleia Geral das Nações Unidas no ano de 1989, instituído pela Convenção Internacional dos Direitos da Criança, elaborado pela ONU. A convenção apontou uma série de direitos fundamentais das crianças, influenciando a concepção da infância e adolescência que passa a ser identificada na legislação brasileira (Azambuja, 2011). O ECA (1990) definiu uma política de atendimento dos direitos da criança e do adolescente através de um conjunto articulado de ações governamentais e não governamentais, rompendo com as práticas assistencialistas e filantrópicas, dando origem ao Sistema de Garantia de Direitos.

Os caminhos trilhados no percurso histórico dos direitos e políticas de atendimento à criança e ao adolescente foram importantes para alcançar os direitos e a atual atenção preconizada à esta população. Contudo, assegurar os direitos preconizados no ECA é um desafio que exige rupturas com relação ao modelo anteriormente vigente e o desenvolvimento de novas práticas (França \& Ferreira, 2012; Lima \& Veronese, 2012). 


\section{O Sistema de Garantia de Direitos: Perspectiva de uma Atuação em rede}

O Sistema de Garantia de Direitos (SGD) é resultado de uma grande mobilização marcada pela constituição de 1988 (Constituição da República Federativa do Brasil, 1988) e pela promulgação do ECA (1990). Ele garante tanto os direitos universais a todas as crianças e adolescente como a proteção especial para aqueles que foram ameaçados ou violados em seus direitos. Este sistema se constitui através da integração de um conjunto de atores, instrumentos e espaços institucionais formais e informais com papéis e atribuições específicas e definidas no ECA (1990).

Os parâmetros para a instituição e o fortalecimento do SGD foram preconizados pela Resolução $n^{\circ} 113$, de 19 de abril de 2006, do Conselho Nacional dos Direitos da Criança e do Adolescente (CONANDA). De acordo com esta resolução, o SGD é responsável por colocar todas as crianças e adolescentes a salvo de todas as formas de violações de direitos e garantir a apuração e reparação dessas" (art. 2). Neste sentido, o Sistema está estruturado em três eixos estratégicos: promoção, defesa e controle da efetivação dos direitos. O eixo da promoção dos direitos é formado por órgãos governamentais e não governamentais que atuam através da formulação e implementação de políticas públicas voltadas para o atendimento à criança $\mathrm{e}$ ao adolescente. Neste eixo, trabalham os órgãos que executam as políticas públicas nas áreas da educação, saúde, assistência social, entre outros, bem como os conselhos partidários de deliberação sobre as diretrizes dessas políticas, as entidades públicas e privadas de prestação de serviços e os Conselhos de Direitos da Criança e do Adolescente (Aquino, 2004; Baptista, 2012). O eixo da defesa, formado pelo Judiciário, Ministério Público, Secretarias de Justiça, Conselheiros Tutelares e órgãos de defesa da cidadania, visa assegurar o cumprimento e a exigibilidade dos direitos estabelecidos na legislação, responsabilizando de maneira judicial, administrativa ou social às famílias, ao poder público e ou à própria sociedade pela violação destes (Aquino, 2004; Baptista, 2012). Por fim, o eixo de controle é composto pelos organismos da sociedade civil representados nos fóruns de direitos e outras instâncias não-governamentais, assim como os conselhos de direitos e de políticas setoriais (Aquino, 2004).

A prática do Sistema é consolidada através de redes de proteção que visam à promoção do atendimento integral às necessidades da população infanto-juvenil (Aquino, 2004). A "noção de rede", segundo Aquino (2004) "permite traduzir com mais propriedade a trama de conexões interorganizacionais em que se baseia o sistema de garantia dos direitos de crianças e adolescentes" (p. 329), tendo em vista que abrange a complexidade das relações acionadas pelos atores de cada organização para garantir os direitos. Deste modo, as redes de proteção representam "o aspecto dinâmico do sistema, conformado a partir das conexões entre atores que compartilham um sentido de ação" (Aquino, 2004, p. 329).

A literatura aponta que, de modo geral, o trabalho em rede envolve uma construção coletiva através de relacionamentos, negociações, interesses compatíveis, acordos, movimentos de interação e também de adesão (Moreira, Muller, \& Da Cruz, 2012). As ações em rede abrangem a recepção e o encaminhamento propriamente dito dos casos, discussão dos casos por todos os profissionais envolvidos no atendimento, acesso aos prontuários e processos judiciais, visitas interinstitucionais (acolhimento residencial ou institucional, fórum, escola, domicilio), debates tematizados, participação em espaços de discussão política e troca de saberes e experiências (Lorencini, Ferrari, \& Garcia, 2002). Deste modo, exercer a articulação da rede implica agendas em comum, tanto para o desenvolvimento de acordos em relação aos desafios e ações, como para o acompanhamento dos casos e avaliações de fluxos (Conselho Federal de Psicologia [CFP], 2012). Nesse sentido, a rede de proteção representa uma nova forma de atenção voltada para a infância e adolescência, que visa à atuação integrada e articulada das instituições, órgãos e atores que atuam no atendimento de crianças, adolescentes e suas famílias (Oliveira, Pfeiffer, Ribeiro, Golçalves, \& Ruy, 2006). A possibilidade da prática de redes permite "repen- 
sar formas instituídas de atuação e buscar formas instituintes, que rompam com as práticas tradicionais, como a busca ativa, a transversalidade de saberes, a articulação com movimentos sociais" (Grossi, Perdersen, Vincensi, \& Almeida, 2012, p. 274).

A importância do atendimento em rede para o enfretamento do fenômeno da violência, bem como, para a efetividade das ações de proteção das crianças e adolescentes é discutida pela literatura (Azambuja, 2011; E. T. Faleiros, 2003; Faraj \& Siqueira, 2012; Furniss, 1993; Lopes, Silva, Dias, \& Arpini, 2012; Rizzini et al., 2007; Sanderson, 2004/2005). A articulação dos órgãos, instituições e atores que atendem a criança e adolescente em suspeita ou situação de violação de direitos faz-se necessária, pois ações isoladas e fragmentadas não se mostram suficientes na prevenção, na responsabilização do agressor e no atendimento da vítima (Ipollito, 2004). Além disso, podem causar um dano adicional à criança e ao adolescente, acentuando o trauma da situação de violência (Furniss, 1993; Sanderson, 2004/2005).

Apesar da atual legislação voltada para a infância e adolescência buscar romper com as antigas práticas presentes no percurso histórico e estudos científicos apontarem a importância do atendimento em rede, pesquisas vêm mostrando a falta de articulação das instituições e dos órgãos que integram a rede (Faraj \& Siqueira, 2012; Lopes et al., 2012). Considera-se que a efetivação dos direitos e a superação das situações de violência requerem o conhecimento e a reflexão de atores que compõem a rede. Neste sentido, este estudo objetivou conhecer a percepção dos profissionais que atuam no eixo da defesa acerca da rede de proteção nos casos acompanhados pelo Sistema de Garantia de Direitos.

\section{Método}

\section{Delineamento e Participantes}

Trata-se de um estudo qualitativo, de caráter descritivo e exploratório realizado nos Conselhos Tutelares (leste, centro e oeste), Delegacia de Proteção à Criança e ao Adolescente e Minis- tério Público de um município do Rio Grande do Sul, órgãos integrantes do SGD. Participaram do estudo, três conselheiros tutelares, um delegado de polícia, um promotor de justiça, totalizando cinco participantes. O critério de inclusão adotado foi ser promotor de justiça que atua na Promotoria Especializada de Defesa da Infância e Juventude, delegado de polícia da Delegacia de Proteção à Criança e ao Adolescente e conselheiro tutelar no exercício da função de coordenador. Dois conselheiros tutelares possuíam Ensino Superior completo, sendo um especialista em psicopedagogia. Um operador do direito era mestre em direito e outro especialista na área da infância e juventude pela Escola Superior do Ministério Público. O tempo de atuação dos profissionais nos órgão variou de dois a 17 anos. Para manter os cuidados éticos, principalmente no que se refere ao sigilo dos participantes, optou-se por não identificar o sexo e a atividade profissional dos participantes. Dessa forma, os profissionais entrevistados serão apresentados da seguinte forma: P1, P2, P3, P4, P5.

\section{Instrumento}

Foram realizadas entrevistas semi-estruturadas a fim de se obter em profundidade as experiências dos profissionais que atuam nos casos de violação dos direitos da criança e o adolescente, realizando-se uma troca dinâmica entre o entrevistador e o entrevistado, promovendo a coleta de informações baseada no livre discurso deste (Bleger, 1993). Os eixos que nortearam as entrevistas foram: percepção acerca da problemática da violação dos direitos de crianças e adolescentes no município; conhecimento dos serviços que compõem a rede de proteção; encaminhamentos que são realizados; definição de rede de proteção; percepção acerca do funcionamento da rede no município; órgãos que compõem a rede; como o profissional se insere na rede; e, percepção sobre o papel do Sistema de Garantia de Direitos.

\section{Procedimentos e Considerações Éticas}

A pesquisa foi respaldada na Resolução n 466 do Conselho Nacional de Saúde (2012) 
e na Resolução no 016 do CFP (2000) que regulamentam a pesquisa em seres humanos. O estudo foi apresentado aos órgãos e após a autorização de cada órgão, o projeto foi submetido ao Comitê de Ética em Pesquisa (CEP) da Instituição onde as pesquisadoras atuam. Com a aprovação do projeto de pesquisa pelo CEP, via Plataforma Brasil (protocolo CAAE número 04974412.4.0000.5346), os profissionais foram contatados e as entrevistas foram agendadas e realizadas individualmente no local de trabalho dos participantes e com duração de aproximadamente uma hora. No momento da entrevista, foi estabelecido o rapport, foram esclarecidos os objetivos da pesquisa e foi solicitado à assinatura do Termo de Consentimento Livre e Esclarecido. Após este momento, iniciou-se a entrevista propriamente dita e o gravador foi acionado.

\section{Análise dos Dados}

As entrevistas foram transcritas na íntegra e analisadas qualitativamente (Bardin, 1977/2011). Num primeiro momento, realizou-se uma análise de cada entrevista individualmente, através de uma leitura atenta e detalhada e num segundo momento, procedeu-se a análise da totalidade do material obtido com as entrevistas. Essa análise detalhada permitiu a construção das categorias, as quais foram se delineando considerando a frequência com que a temáticas se fizeram presentes, se tornaram significativas e a força discursiva com a qual os participantes abordaram determinados temas, dando origem a quatro categorias. Utilizaram-se para nomeá-las falas dos participantes que foram consideradas representativas do conteúdo a ser trabalhado, sendo que após a vinheta, a definição da categoria é abordada. As categorias encontradas foram: (a) "Estatuto é um divisor de águas": Mudança de paradigma na atenção à infância e adolescência; (b) "Uma teia de comunicação permanente": A compreensão da rede de proteção; (c) "A gente tá trabalhando mais em conjunto": Percepção sobre o funcionamento da rede de proteção; (d) "Vários desafios": A efetivação da garantia dos direitos da criança e do adolescente.

\section{Resultados e Discussão}

\section{"O Estatuto é um Divisor de Águas": Mudanças de Paradigma na Atenção à Infância e Adolescência}

Esta categoria apresenta dados referentes às mudanças acerca da política de atendimento voltada para a infância e adolescência a partir do ECA (1990) na visão dos entrevistados. A partir dos relatos, pode-se identificar que os participantes percebiam o avanço que o ECA (1990) representou na promoção dos direitos e na atenção oferecida à infância e à adolescência. Nesse sentido, alguns profissionais assinalaram que a promoção dos direitos das crianças e dos adolescentes, em especial dos que vivenciaram uma situação de violência, está atrelada à oferta de políticas públicas e uma atuação em rede, na qual o funcionamento implicava investimento da esfera pública, conforme observado nas falas:

O Estatuto é um divisor de águas, principalmente no âmbito jurídico. Então, nós demoramos, digamos assim, bastante no âmbito jurídico pra evoluir nessa percepção de que crianças e adolescentes não são adultos menores, né. E sim são pessoas que estão em condições peculiares e que precisam de uma proteção diferenciada. (P4)

. . . a promoção dos direitos só vai conseguir existir no momento em que existir uma estrutura no município para garantir esses direitos . . . não adianta eu receber uma demanda . . uma notificação de violência ou até mesmo de alguma outra coisa se eu não tiver pra onde encaminhar. Daí, nesse momento, eu não vou conseguir garantir o direito, eu não vou conseguir ter a proteção integral, por que a proteção integral depende da nossa rede. (P3)

$\mathrm{Na}$ concepção dos profissionais entrevistados, nos casos de violência envolvendo crianças e adolescentes, o município conta com uma rede composta por diversos órgãos, serviços e instituições, dentre os citados destacaram-se, o Juizado da Infância e Juventude, Promotoria Especializada, Delegacia de Proteção à Criança e ao Adolescente, Conselho Tutelar, serviços de proteção social básica (CRAS) e especial (CRE- 
AS e acolhimento institucional) e instituições de saúde e educação. Assim, observou-se que todos os atores entrevistados se sentiam inseridos na rede do município e, portanto responsáveis pela promoção e garantia dos direitos das crianças e dos adolescentes.

Nesta perspectiva, a frase "o estatuto assim é a nossa bíblia" (P3) exemplifica a concepção compartilhada entre os profissionais de que o ECA (1990) deve embasar as intervenções voltadas para a população infanto-juvenil em situação de violência, sendo estas sustentadas pela ótica do SGD. Neste sentido, as ações nos casos de violência requerem, sobretudo, a compressão por parte de atores do SGD acerca da rede de proteção voltada às crianças e aos adolescentes em situação de violência.

\section{"Uma Teia de Comunicação Permanente": A Compreensão da Rede de Proteção}

Essa categoria apresenta dados que remetem à definição de rede e o conhecimento sobre sua função. Para os profissionais entrevistados, a rede de proteção representava um trabalho em conjunto, em que há diálogo e comunicação permanente entre os atores, instituições e órgãos, que tem por escopo a proteção das crianças e dos adolescentes. Isto pode ser observado nos relatos: "[a rede] é todo mundo engajado pela mesma causa que é a proteção da criança e do adolescente" (P3); "[a rede] é uma ligação dos serviços" (P1);

A rede é uma teia de comunicação permanente entre os órgãos que compõem, com pessoas comprometidas né, com pessoas responsáveis, com pessoas que entendam a importância e a gravidade daquilo que nós estamos nos propondo a combater né. Por que a rede de proteção, se ela é chamada assim, é por que nós precisamos proteger alguém né. E esse alguém é a criança e o adolescente. (P4)

União. Eu acho que tem que ter união entre todas as instituições, se não tiver união não tem como funcionar entendeu. Por isso mesmo o nome é rede, tá unido ... tem que ter esse vínculo entre todos. A união faz a força isso é certo. (P2)

As definições de rede de proteção está em sintonia com a legislação e a literatura (Aquino, 2004; E. T. Faleiros, 2003; Oliveira et al., 2006; Rizzini et al., 2007). Para Rizzini et al. (2007), a rede representa relações e interações estabelecidas que visam às ações ou trabalhos conjuntos. De acordo com E. T. Faleiros (2003), as redes se organizam através da articulação de atores e organizações que são capazes de compartilhar e de negociar as responsabilidades para o desenvolvimento de ações conjuntas. Nesta mesma perspectiva, Oliveira et al. (2006) apontaram que a rede é um padrão organizacional que visa a uma tomada de decisão, a uma descentralização e prima pela flexibilidade, autonomia e horizontalidade das relações estabelecidas entre seus membros.

No estudo, pode-se observar que para os atores participantes cada "fio" da rede desempenha um papel específico, ou seja, cada órgão, instituição, organização, serviço têm sua função, porém deve existir uma articulação entre os membros. Este dado vai ao encontro da perspectiva de atuação em rede na qual, cada ator, instituição e órgão participante da rede têm o seu papel, no entanto, a rede compreende uma atuação integrada e intersetorial que envolve todas as instituições que atuam na atenção à criança e ao adolescente (Rizzini et al., 2007).

Um aspecto importante apontado por um dos participantes do estudo acerca da concepção de trabalho em rede é o entendimento de que "é um trabalho gradativo" (P1), ou seja, está em constante construção. Esse aspecto está em sintonia com Oliveira et al. (2006), pois requer mudanças de práticas. Dessa forma, é importante considerar que, apesar do ECA ter surgido a mais de 20 anos no Brasil, é recente a percepção da "potencialidade da atuação em rede como forma ou estrutura de organização capaz de reunir pessoas e instituições em torno de objetivos comuns" (Oliveira et al., 2006, p. 144). Neste sentido, a constituição de uma rede exige, na maioria das vezes, um movimento intenso e contínuo para integrar os diferentes atores e organismos sociais (Njaine, Assis, Gomes, \& Minayo, 2007). 


\section{"A Gente tá Trabalhando Mais em Conjunto": Percepção sobre o Funcionamento da Rede de Proteção}

Essa categoria apresenta dados sobre a percepção dos entrevistados quanto ao funcionamento da rede de proteção nos casos de violação dos direitos das crianças e dos adolescentes, em especial, nos casos de violência. A importância de uma atuação integrada e articulada nos casos de violência envolvendo crianças e adolescentes foi unânime entre os profissionais entrevistados. Estes acreditavam que o município vem realizando ações e intervenções em conjunto nos casos de violência contra a população infanto-juvenil, como pode ser observado na fala: " $a$ rede de um tempo pra cá tá bastante assídua, a gente tá trabalhando mais em conjunto" (P1). Dessa forma, os profissionais percebiam avanços quanto à articulação dos órgãos, instituições e profissionais, assim como a importância dessa articulação para a resolução dos casos atendidos. De acordo com alguns atores da rede:

$A$ rede hoje, a gente teve um avanço muito grande, por que assim oh, a gente tá conseguindo, as pessoas estão entendendo que sem a articulação não se consegue nenhum avanço né, por que a gente precisa de todos os eixos para evoluir. (P3)

Eu acredito que melhorou bastante a rede, melhorou muito. $O$ número de instituições que se adequaram a esta rede e as pessoas estão com mais consciência de que tem que funcionar a rede. Que tem uma rede tem, mas tem que funcionar com todas as instituições interligadas né. (P2)

Os entrevistados ainda afirmaram que a articulação da rede está ocorrendo porque está acontecendo a comunicação, a interação e a responsabilização compartilhada diante dos casos de suspeita ou violação dos direitos das crianças e dos adolescentes. Além disso, eles mencionaram a realização de cursos de capacitação no município que estão abordando a temática da rede de proteção e enfocando o funcionamento desta para a proteção dos direitos dos sujeitos. Este dado vai de encontro ao estudo realizado no mesmo município no ano de 2010 acerca da rede de proteção, o qual apontou a fragmentação e desarticulação da rede (Faraj \& Siqueira, 2012). Portanto, este achado pode indicar um movimento de mudança na atuação por parte dos profissionais no que se refere à articulação da rede.

Os profissionais entrevistados consideraram que uma articulação bem sucedida depende dos órgãos e dos profissionais entenderem e desempenharem as suas funções, interagirem com outros órgãos através de uma comunicação permanente sobre os casos e atuarem de maneira conjunta na resolução dos mesmos. O estudo realizado por Moraes (2012), acerca da rede de proteção voltada para a criança em situação de violência, apontou duas definições de articulação em rede. Uma relacionada ao trabalho organizado e a união de todos os órgãos que atuam no atendimento à criança em situação de violência para elaboração de metas e planos de trabalho e a outra pautada no compromisso dos órgãos que atendem à criança de desenvolverem ações conjuntas através do trabalho em equipe. É importante considerar que o trabalho integrado das instituições e órgãos envolvidos no atendimento à criança e ao adolescente possibilita a obtenção e troca de informações e dessa forma, pode-se ampliar a visão do caso e sistematizar as ações no enfrentamento das situações de violação de direitos (CFP, 2012; Lorencini et al., 2002). Além disso, permite à integração das políticas sociais e rompimento com uma atenção fragmentada no acompanhamento das famílias (CFP, 2012).

Apesar dos avanços identificados, pelos atores entrevistados em relação à rede de proteção, ainda faltam recursos materiais (carros, linha telefônica, etc.) e humanos nos segmentos que compõem à rede, em especial, nos Conselhos Tutelares e nos serviços de proteção social especial (CREAS). De acordo com os profissionais, isso pode comprometer a proteção da criança e do adolescente visto que a falta de materiais e profissionais para atender causa uma demanda muito grande nos serviço e dessa forma, a demora no atendimento e no retorno deste aos órgãos de defesa. A falta de recursos materiais e humanos e a grande demanda de trabalho foram apontadas em estudos que versaram sobre $o$ atendimento e a rede de proteção à criança e ao 
adolescente em situação de violência (Faraj \& Siqueira, 2012; Moraes, 2012; Pedersen, 2010).

Os atores que participaram do estudo também assinalaram alguns fatores que ainda encontravam-se presentes no funcionamento da rede $\mathrm{e}$ que poderiam comprometer o atendimento oferecido no município, dentre eles: a falta de sigilo profissional e o conhecimento deficiente por parte de profissionais do SGD em relação à violência. Outro aspecto diz respeito à comunicação que, embora tenha sido considerada satisfatória e em amplo desenvolvimento, quando há a sua ausência ou é insuficiente entre alguns profissionais e serviços, causa problemas no trabalho em rede. Neste sentido, "serviços têm que se organizar de tal forma que eles consigam se reunir pelo menos uma vez por mês para falar sobre os casos" (P5) e

À princípio, nós deveríamos fazer reuniões, reuniões assim de todo o pessoal da rede, vamos fazer reuniões . . . de dois em dois meses, de três em três meses, com representantes da polícia, representante do Ministério Público, do Conselho Tutelar, dos agentes de saúde... pra gente poder ter assim, até essa familiaridade um com o outro, que às vezes nós não temos... ( (P4)

A falta de comunicação entre os órgãos e serviços da rede de atendimento e de proteção da criança e do adolescente vem sendo apontada na literatura que versa sobre a temática da violência contra a criança e o adolescente (Faraj \& Siqueira, 2012; Pedersen, 2010). Para que a rede de proteção se estabeleça e suas ações sejam eficazes, a comunicação tem um papel fundamental. A comunicação representa ações planejadas e realizadas em conjunto. Além disso, significa o compartilhamento de informações e responsabilidades tendo como foco principal a proteção e o bem-estar da criança e do adolescente (Moreira et al., 2012). Neste contexto, destaca-se a reflexão de um profissional entrevistado:

É uma rede que são vários pontos e esses pontos tem que ser ligados, né? Eu não consigo ter, eu aqui nessa, na ponta da rede eu não consigo falar contigo na outra ponta se eu não passar pelo meio da rede. . . não adianta eu aqui na ponta da rede dizer que tu lá no fim, tu foi culpada de um atendimento ou de um acompanhamento mal sucedido. Eu acho que se eu aqui na ponta fiz um acompanhamento e o meio da rede falhou, não é tu a culpada. Então assim, essa questão da comunicação e dos retornos de um órgão para o outro. É dessa forma que a gente vai conseguir ter êxito no final. Então, é bem isso mesmo, é a comunicação. (P3)

O estudo de Pedersen (2010) apontou como dificuldades e limites da atuação em rede, entre outras, a falta de organização desta para garantir o feedback e estabelecer o processo de referência e contra-referência, bem como o conhecimento e o entendimento das atribuições de cada instituição. O estudo realizado por Njaine et al. (2007) mostrou outros problemas que prejudicam o trabalho em rede como: a disparidade de compreensão, divergências políticas, vaidades pessoais, conflitos de papéis entre as entidades participantes. Além disso, a rotatividade dos profissionais que atuam nas instituições que atendem crianças e adolescentes e as diferentes formas de trabalho também se destacaram como fatores que interferem na atuação em rede.

\section{"Vários Desafios": A Efetivação da Garantia dos Direitos da Criança e do Adolescente}

Esta categoria apresenta os dados quanto aos desafios referentes à efetivação da garantia dos direitos da criança e do adolescente. Apesar de o Brasil ter uma legislação considerada avançada, que estabelece a proteção à criança e ao adolescente, ainda existe muito a ser realizado para que os direitos sejam efetivados (França \& Ferreira, 2012; Lima \& Veronese, 2012). Os profissionais entrevistados apontaram o fortalecimento da rede de proteção como um desafio na garantia dos direitos: "eu acho que é um desafio muito grande, o fortalecimento dos vínculos, o fortalecimento da rede" $(\mathrm{P} 3)$; "a rede de proteção tem que se fortalecer. Nós precisamos estar cada vez mais unidos" (P4). Na concepção de Lima e Veronese (2012), as práticas do modelo menorista representam a maior dificuldade de efetivação dos novos direitos previstos no ECA (1990). Dessa forma, as crianças e os adolescen- 
tes são constantemente "afrontados" nos seus direitos, pois a família, Estado e Sociedade ainda não se adaptaram à nova exigência de uma nova prática e atuação dessa legislação.

Neste contexto, outro desafio relevante apontado pelos atores entrevistados refere-se ao atendimento à família. Isso pode ser observado no relato:

o desafio nosso é a família. Tu vai trabalhar a criança e o adolescente, tu vai trabalhar a violência, mas a criança e o adolescente vai acabar voltando para aquele lar, vai acabar voltando para aquela casa, para aquela família. (P1)

O profissional ainda complementou que a familia tem autonomia, tem total responsabilidade pela educação do seu filho. Nós somos órgãos de encaminhamento e aplicadores de medidas de proteção, mas a família é em primeira instância a responsável pela criança e adolescente, são eles que têm que mediar os cuidados. (P1)

Nesta perspectiva, Pedersen e Grossi (2011) apontaram que através do apoio do Estado e do trabalho realizado por diversos profissionais e instituições, a família poderá garantir os direitos e a proteção da população infanto-juvenil. No entanto, para isso, torna-se necessário que as necessidades básicas da família sejam satisfeitas (saúde, alimentação, moradia, entre outras). $\mathrm{O}$ atendimento à família ainda é deficiente e a inclusão desta nas ações ainda é um desafio (Njaine et al., 2007).

A prevenção da violência também foi apontada como um desafio na visão dos profissionais entrevistados. Para estes, o avanço na esfera dos direitos está relacionado também às ações de prevenção das situações de violência pelos profissionais da rede de proteção. Para um dos profissionais, "o estado tem que atuar nas duas frentes sempre. Na prevenção, através de politicas públicas, e também na repressão. Então, ocorrendo crime, o estado tem que se fazer presente através da polícia, através do judiciário" (P4). Destaca-se que, a prevenção da violência pode ser desenvolvida em três modalidades, primária, secundária e terciária, e também deve envolver diversos atores e instituições (Branco \&
Tomanik, 2012; Njaine et al., 2007). Neste sentido, para prevenir novos casos de violência, ainda se faz necessário promover o trabalho conjunto dos agentes da rede, bem como, incluir a família nas ações de prevenção e proteção (Njaine et al., 2007).

Outro aspecto significativo levantado pelos profissionais entrevistados se refere à punição do agressor da violência, contemplado no eixo da defesa do SGD. Conforme um entrevistado, "ele foi lá abusou, agrediu, bateu, até uma violência psicológica, que muitas vezes é pior que uma violência fisica, né, muitas vezes até é muito pior, e a gente não tem nenhum retorno de punição" (P3). Na concepção deste profissional, "não adianta somente a gente fazer, fazer campanha para que as pessoas denunciem e a gente não dar esse retorno para a sociedade" (P3). M. L. Santos (2003) salienta que o grande problema de nosso país é a impunidade, pois apesar da legislação vigente, em grande parte dos casos de violência contra a criança e o adolescente, o agressor ou abusador fica impune, o que facilita o aumento da violência contra esta população. Os estudos de Branco e Tomanik (2012) e de Dell'Aglio, Moura e Santos (2011) apontaram a responsabilização dos agressores como um dos eixos do enfrentamento da violência. Ainda, destacaram que o atendimento psicológico oferecido aos atores da violência pode ser um recurso para evitar casos novos. Deve-se possibilitar a reflexão dos agressores/abusadores acerca de seus comportamentos a fim de evitar a reincidência da violência.

Diante do exposto, a efetivação da garantia dos direitos da criança e do adolescente passa pela existência da rede de proteção, com seus diversos atores atuando na prevenção, responsabilização e atendimento dos que tiveram seus direitos violados. Salienta-se que, a Constituição Federal (1988) e o ECA (1990) "não podem ser vistos como pontos de chegada. Representam, de um lado, o aprendizado do passado e, de outro, simbolizam a força propulsora de um novo tempo, que apenas lança seus primeiros alicerces na história do Brasil" (Azambuja, 2011, p. 49). Dessa forma, para que os direitos das crianças e adolescentes sejam garantidos, cabe a todos ze- 
lar e trabalhar para que a política seja colocada em prática.

\section{Considerações Finais}

O estudo permitiu uma discussão sobre a rede de proteção de crianças e adolescentes a partir dos profissionais que integram o eixo de defesa do Sistema de Garantia de Direitos. Possibilitou, a partir da descrição e reflexão do percurso histórico da constituição dos direitos da criança e do adolescente e das políticas de atenção voltadas a esse público (Marcílio, 2006; Rizzini \& Rizzini, 2004), vislumbrar o grande avanço quanto à legislação que se vivencia na atualidade. De um tempo em que os jovens não eram reconhecidos como cidadãos e nem merecedores de direitos, mas sim alvo de políticas puramente assistenciais, filantrópicas e caritativas até a atualidade, em que esse público é foco de legislação específica que o considera sujeitos de direitos e em situação peculiar de desenvolvimento. Os profissionais entrevistados consideraram o ECA (1990) um marco legal e histórico, e de fato, representa um instrumento contemporâneo jurídico de promoção e proteção dos direitos da criança e do adolescente no Brasil. Desde a sua implantação, medidas começaram a ser adotadas, principalmente no enfrentamento da violência contra a criança e o adolescente, como mudanças nas políticas e ações de proteção destinadas a esta população.

O estudo possibilitou evidenciar que os participantes entrevistados que integram o Sistema de Garantia de Direitos compreendem a política de atendimento preconizada pelo ECA (1990) e vêm tentando desenvolver um trabalho articulado nos casos de violência contra a população infanto-juvenil. Demonstraram conhecimento sobre a função da rede de proteção, o avanço que o ECA representou, o estabelecimento da referência e contra-referência no atendimento a partir de instituições interligadas, bem como a importância da comunicação. Pode-se observar, através dos relatos, fragilidades quanto à dificuldade de comunicação entre os atores que compõem a rede. Cabe destacar que apesar de mencionado um avanço na comunicação entre os atores do eixo de defesa do Sistema de Garantia de Direitos quando comparada ao momento anterior à efetivação da política que estabeleceu o trabalho em rede (V. P. Faleiros, 2004; V. P. Faleiros \& Faleiros, 2008; Marcílio, 2006; Rizzini \& Rizzini, 2004), ainda é necessário fortalecer um trabalho integrado e articulado, favorecendo à comunicação.

Os desafios mencionados no trabalho em rede foram inúmeros e esclareceram quanto aos pontos que devem ser trabalhados. A ausência de atendimento voltado para o agressor, a importância de investir mais nas famílias e a escassez de ações preventivas são aspectos que devem ser alvo da atuação do SGD. As famílias poderiam ser acompanhadas a partir de um olhar mais atento, contudo a demanda das vítimas não tem permitido que um trabalho mais global seja realizado com as famílias (Faraj \& Siqueira, 2012). Da mesma forma, ações preventivas deveriam fazer parte do trabalho desses profissionais, pois são consideradas fundamentais para a mudança de comportamento no campo da garantia de direitos.

Trabalhar em rede implica tanto mudanças na prática dos profissionais envolvidos nos casos de suspeita ou violação de direitos, como também investimentos dos gestores municipais em recursos e capacitações periódicas que visem a esta nova estratégia de trabalho. Profissionais com uma boa formação e com oportunidades frequentes de capacitação e aprofundamento teórico-prático, sobretudo na área dos direitos da criança e do adolescente, serão capazes de romper com o isolamento e compartilhar saberes, discutir situações, tomar decisões em conjunto, ou seja, sair das "caixinhas", muitas vezes construídas pelos próprios núcleos de conhecimento. Atuar em rede implica investimento profissional, engajamento e acima de tudo consciência de que o trabalho conjunto e articulado possibilita melhor enfrentar o fenômeno da violência, assim como, garantir e reparar os direitos de quem foi violado. Somente desta forma, será possível promover novas práticas e superar as fragiliades existentes na rede de atendimento e de proteção à criança e ao adolescente, evitando assim, o retrocesso no atendimento voltado para esta população. 
Como limitação do estudo, pode-se considerar a inclusão de apenas representantes do eixo da defesa do Sistema de Garantia de Direitos. Estudos que incluíssem os eixos da promoção e controle poderiam contribuir para ampliar a compreensão da rede de proteção e de seu funcionamento. Considerando as especificidades de cada eixo e os diferentes profissionais que os integram, a inclusão de outros atores como participantes, sem dúvida ampliaria as possibilidades de melhor compreender o fenômeno aqui estudado. Com este estudo, entende-se que a discussão que envolve problemática da violência contra a criança e o adolescente e o Sistema de Garantia de Direitos não se esgota, identificando-se a necessidade de outras pesquisas que versam sobre as vivências e percepções de profissionais que atuam no atendimento à criança e ao adolescente em situação de violência.

\section{Referências}

Aquino, L. M. C. (2004). A rede de proteção a crianças e adolescentes, a medida protetora abrigo e o direito à convivência familiar e comunitária: A experiência em nove municípios. In E. R. A. da Silva (Ed.), $O$ direito à convivencia familiar e comunitária: Os abrigos para crianças e adolescentes no Brasil (pp. 325-365). Brasília, DF: Instituto de Pesquisa Econômica Aplicada.

Azambuja, M. R. (2011). Inquirição da criança vítima de violência sexual: Proteção ou violação de direitos? Porto Alegre, RS: Livraria do Advogado.

Baptista, M. V. (2012). Algumas reflexões sobre o sistema de garantia de direitos. Serviço Social \& Sociedade, 109, 179-199. doi:10.1590/S010166282012000100010

Bardin, L. (2011). Análise de conteúdo (Ed. rev., atual. e ampl., L. A. Reto \& A. Pinheiro, Trads.). Lisboa, Portugal: Edições 70. (Original publicado em 1977)

Bleger, J. (1993). Temas de psicologia: Entrevista e grupos. São Paulo, SP: Martins Fontes.

Branco, M. A. O., \& Tomanik, E. A. (2012). Violência doméstica contra crianças e adolescentes: Prevenção e enfrentamento. Psicologia \& Sociedade, 24(2), 402-411. doi:10.1590/S010271822012000200018
Conselho Federal de Psicologia. (2000). Resolução $n^{o}$ 016/2000 de 20 de dezembro de 2000. Brasília, DF: Autor

Conselho Federal de Psicologia. (2012). Referências técnicas para prática de psicólogas (os) no centro de referência especializado da assistência social-CREAS. Brasília, DF: Autor.

Conselho Nacional de Saúde. (2012). Resolução $n^{o}$ 466, de 12 de dezembro de 2012. Brasília, DF: Autor.

Conselho Nacional dos Direitos da Criança e do Adolescente. (2006). Resolução $n^{\circ} 113$, de 19 de abril de 2006. Brasília, DF: Autor.

Constituição da República Federativa do Brasil. (1988, 5 out.). Brasília, DF: Presidência da República.

Decreto n ${ }^{\circ} 17943-A$, de 12 de outubro de 1927. (1927, 31 dez.). Codigo dos Menores. Coleção das Leis do Império do Brasil.

Decreto-Lei n ${ }^{\circ}$ 2.848. (1940, 31 dez.). Código Penal. Diário Oficial da União.

Decreto-lei no 3.733/41. (1941). Institui o Serviço de Assistência ao Menor.

Dell'Aglio, D. D., Moura, A., \& Santos, S. S. (2011). Atendimento a mães de vítimas de abuso sexual e abusadores: Considerações teóricas e práticas. Psicologia Clinica, 23(2), 53-73.

Estatuto da Criança e do Adolescente. (1990, 27 set.). Lei Federal n. 8.069, de 13 de julho de 1990. Dispõe sobre o Estatuto da Criança e do Adolescente e dá outras providencias. Diário Oficial da União.

Faleiros, E. T. (2003). O abuso sexual contra crianças e adolescentes: Os (des) caminhos da denúncia. Brasília, DF: Presidência da República, Secretaria Especial dos Direitos Humanos.

Faleiros, V. P. (2004). Infância e adolescência: Trabalhar, punir, educar, assistir, proteger. Revista Agora: Políticas Públicas e Serviço Social, 1(1), 1-9.

Faleiros, V. P., \& Faleiros, E. S. (2008). Escola que protege: Enfrentando a violência contra crianças e adolescentes (2. ed.). Brasília, DF: Ministério da Educação, Secretaria de Educação Continuada, Alfabetização e Diversidade.

Faraj, S. P., \& Siqueira, A. C. (2012). O atendimento e a rede de proteção da criança e do adolescente vítima de violência sexual na perspectiva dos 
profissionais do CREAS. Barbarói, 37, 67-87. doi:10.17058/barbaroi.v0i37.2097

Fonseca, C. (2004). Os direitos da criança - Dialogando com o ECA. In C. Fonseca, V. Terto, \& C. F. Alves (Eds.), Antropologia, diversidade e Direitos Humanos (pp. 103-115). Porto Alegre, RS: Editora da Universidade Federal do Rio Grande do Sul.

França, R. M. S., \& Ferreira, M. D. A. M. (2012). As políticas públicas e a efetivação de direitos humanos pós Constituição Brasileira de 1988. Emancipação, 12(2), 181-191. doi:10.5212/ emancipação.v12i2.1799

Furniss, T. (1993). Abuso sexual da criança: Uma abordagem multidisciplinar (M. A. V. Veronese, Trad.). Porto Alegre, RS: Artes Médicas.

Giaqueto, A. (2006). Caminhos para a atenção à infância e adolescência no Brasil: As políticas sociais e as legislações. Revista Agora: Política Pública e Serviço Social, 2(4), 1-18.

Grossi, P. K., Perdersen, J. R., Vincensi, J. G., \& Almeida, M. S. (2012). Prevenção da violência contra mulheres: Desafios na articulação de uma rede intersetorial. Athenea Digital, 12(3), $267-$ 277. doi:10.5565/rev/athenead/v12n3.1112

Ipollito, R. (Ed.). (2004). Guia escolar: Método para identificação de sinais de abuso e exploração sexual de crianças e adolescentes. Brasília, DF: Presidência da República, Secretaria do Especial dos Direitos Humanos.

Lei $\mathrm{n}^{\mathrm{o}} 4.513$ de $1^{\circ}$ de dezembro de 1964. (1964, 4 dez.). Autoriza o Poder Executivo a criar a Fundação Nacional do Bem-Estar do Menor, a ela incorporando o patrimônio e as atribuições do Serviço de Assistência a Menores, e dá outras providências. Diário Oficial da União.

Lei $\mathrm{n}^{\circ}$. 6.697, de 10 de outubro de 1979. (1979, 11 de out.). Institui o Código de Menores. Diário Oficial da União.

Lima, F. S., \& Veronese, J. R. P. (2012). Os direitos da criança e do adolescente: A necessária efetivação dos direitos fundamentais: Vol. 5. Pensando o Direito no Século XXI. Florianópolis, SC: Fundação Boiteux.

Lopes, M. D. C., Silva, M. L., Dias, H. Z. J., \& Arpini, D. M. (2012). Significados atribuídos por profissionais à violência contra crianças e adolescentes: Uma análise dos estudos atuais (Edição especial). Barbarói, 36, 56-69.
Lorencini, B. D. B., Ferrari, D. C. A., \& Garcia, M. R. C. (2002). Conceito de redes. In D. C. A. Ferrari \& T. C. C. Vecina (Eds.), O fim do silencio na violência familiar: Teoria e prática (pp. 298310). São Paulo, SP: Agora.

Marcílio, M. L. (2006). História social da criança abandonada (2. ed.). São Paulo, SP: Hucitec.

Mendes, L. M. (2008). Violência sexual infanto-juvenil no Brasil: Uma análise sobre a ótica jurídica. In L. M. Mendes \& N. A. Marcheza (Eds.), Expressão de violência e seu enfrentamento no CREAS/Centro de Referencia Especializado da Assistência Social (pp. 217-239). Passo Fundo, RS: Méritos.

Moraes, C. A. (2012). Violência doméstica contra a criança e rede de proteção social: Uma análise sobre articulação em rede. Serviço Social em Revista, 14(2), 119-144. doi:10.5433/1679$-4842.2012 \mathrm{v} 14 \mathrm{n} 2 \mathrm{p} 119$

Moreira, E. P., Muller, E. L., \& Da Cruz, L. R. (2012). Centro de referência especializado da assistência social: Pesquisa-intervenção na rede de proteção à infância e adolescência (Edição especial). Barbarói, 36, 70-82.

Njaine, K., Assis, S. G., Gomes, R., \& Minayo, M. C. S. (2007). Redes de prevenção à violência: Da utopia à ação. Ciência \& Saúde Coletiva, 11(Supl.), 1313-1322. doi:10.1590/S141381232006000500020

Oliveira, V. L. A., Pfeiffer, L., Ribeiro, C. R., Golçalves, M. T., \& Ruy, I. A. E. (2006). Redes de Proteção: Novo paradigma de atuação experiência de Curitiba. In C. A. Lima (Ed.), Violência faz mal à saúde (pp. 143-149). Brasília, DF: Ministério da Saúde.

Pedersen, J. R. (2010). Abuso sexual intrafamiliar: Do silêncio ao seu enfrentamento (Dissertação de mestrado, Faculdade de Serviço Social, Pontifícia Universidade Católica do Rio Grande do Sul, Porto Alegre, RS, Brasil).

Pedersen, J. R., \& Grossi, P. K. (2011). O abuso sexual intrafamiliar e a violência estrutural. In M. R. F. Azambuja \& M. H. M. Ferreira (Eds.), Violência sexual contra crianças e adolescentes (pp. 25-34). Porto Alegre, RS: Artmed.

Rizzini, I. (2002). A criança e a Lei no Brasil: Revisitando a história (1822-2000) (2. ed.) Brasília, DF: Fundo das Nações Unidas para a Infância. 
Rizzini, I., \& Rizzini, I. (2004). A institucionalização de crianças no Brasil: Percurso histórico e desafios do presente. Rio de Janeiro, RJ: Editora da Pontifícia Universidade Católica do Rio de Janeiro.

Rizzini, I., Rizzini, I., Naiff, I., \& Baptista, R. (Eds.). (2007). Acolhendo crianças e adolescentes: Experiências de promoção de direitos a convivência familiar e comunitária no Brasil (2. ed.). São Paulo, SP: Cortez.

Sanderson, C. (2005). Abuso sexual em crianças: Fortalecendo pais e professores para proteger crianças contra abusos sexuais e pedofilia (D. C. A. Ferrari, Trad.). São Paulo, SP: M. Books do Brasil Editora. (Original publicado em 2004)
Santos, C. M. A. (2005). A criança como sujeito de direito: O longo caminho da história. In G. Scobernatti (Ed.), Violência intrafamiliar: Teoria e prática - Uma abordagem interdisciplinar (pp. 37-69). Pelotas, RS: Armazém Literário.

Santos, M. L. (2003). A realidade infanto-juvenil e o ECA. Direito em Debate, 20, 169-181.

Recebido: $15 / 12 / 2014$

$1^{a}$ revisão: $10 / 06 / 2015$

Aceite final: 17/06/2015 